\title{
WEB Device for Endovascular Treatment of Wide-Neck Bifurcation Aneurysms
}

\author{
B. Lubicz, B. Mine, L. Collignon, D. Brisbois, G. Duckwiler, and C. Strother
}

\begin{abstract}
BACKGROUND AND PURPOSE: The WEB is an intrasaccular flow disrupter dedicated to EVT of IA. We report our initial experience in a series of patients treated with this device.

MATERIALS AND METHODS: This prospective study was approved by the authors' ethical committees. Nineteen patients with 20 unruptured wide-neck bifurcation IAs were treated by WEB placement. Technical issues, immediate posttreatment angiographic findings, and clinical and imaging follow-up at 3, 6, and 12 months were assessed.

RESULTS: Failure of WEB placement occurred in 1 case because of unavailability of a suitably sized device. Embolization was successful in 18 patients with $19 \mathrm{IAs}$, and it required additional stent placement and/or coiling in 3 cases at the acute phase and in 1 case at follow-up. Two patients experienced a symptomatic complication, and 16 patients had normal neurologic examination findings at discharge. Immediate anatomic outcome showed 1 complete occlusion, 13 near-complete occlusions, and 5 incomplete occlusions. At follow-up, 17 patients had normal neurologic examination findings and 1 retained a hemiparesis. Angiographic controls were obtained in all patients (mean, 6 months), and they showed stable or improved results in all except 4 cases, including 2 complete occlusions, 15 near-complete occlusions, and 2 incomplete occlusions.
\end{abstract}

CONCLUSIONS: In this initial series of patients, EVT of wide-neck bifurcation IAa with the WEB was feasible. Further studies are needed to evaluate the indications, safety, and efficacy of this new technique.

ABBREVIATIONS: $\mathrm{ACT}=$ activated clotting time; $\mathrm{EVT}=$ endovascular treatment; $\mathrm{IA}=$ intracranial aneurysm; $\mathrm{mRS}=$ modified Rankin Scale; WEB = Woven EndoBridge Aneurysm Embolization Device

$\mathrm{T}$ he WEB (Sequent Medical, Palo Alto, California) is an intrasaccular flow disrupter dedicated to IA treatment. ${ }^{1,2}$ It is an intrasaccular braided-wire device designed to provide disruption of flow through the aneurysm ostium, and it is intended as a standalone therapy. Because the WEB is intrasaccular and presents an even metal mesh surface to the parent artery lumen, similar but even smoother and with less porosity than a coil-packed aneurysm, there is no need for antiplatelet therapy. Further, the device seems suitable for use in a broad range of aneurysms, including bifurcation-type morphologies, and does not place adjacent perforating arteries at risk. Last, the WEB is designed to cause

Received June 19, 2012; accepted after revision August 23.

From the Department of Neuroradiology (B.L., B.M., D.B.), Erasme University Hospital, Brussels, Belgium; Department of Radiology (L.C.), Centre Hospitalier Régional de la Citadelle, Liège, Belgium; Department of Interventional Neuroradiology (G.D.), University of California, Los Angeles, Los Angeles, California; and Department of Radiology (C.S.), University of Wisconsin School of Medicine and Public Health, Madison, Wisconsin.

Please address correspondence to Boris Lubicz, MD, Service de Radiologie, Hôpital Erasme, 808 route de Lennik, 1070 Bruxelles, Belgium; e-mail: blubicz@ulb.ac.be

http://dx.doi.org/10.3174/ajnr.A3387 prompt aneurysm occlusion, rendering it appropriate for use in ruptured aneurysms. The aim of this study was to report our initial clinical experience with the WEB for EVT of wide-neck bifurcation IAs.

\section{MATERIALS AND METHODS Population}

Between January 2011 and June 2012, nineteen patients with 20 IAs were treated by WEB placement in 2 different hospitals. Approval from both ethics committees was obtained for this prospective study, and the subjects gave informed consent. Therapeutic alternatives were discussed between neurosurgical and neurointerventional teams in a multidisciplinary decision-making process. Only patients with unruptured, bifurcation/terminal-type IAs, having wide-necks (neck $>4 \mathrm{~mm}$ or neck/dome ratio $>0.7$ ) were included. We considered these aneurysms to have a high likelihood of failure and/or recurrence after treatment with conventional endovascular techniques.

There were 14 women and 5 men with a mean age of 54 years (range, 35-71 years). Clinical presentation and aneurysms char- 
Table 1: Clinical presentation and aneurysm characteristics in 19 patients with 20 intracranial aneurysms treated by WEB placement

\begin{tabular}{|c|c|c|c|c|c|c|}
\hline \multirow[b]{2}{*}{ No. } & \multirow[b]{2}{*}{$\begin{array}{c}\text { Age }(y r) / \\
\text { Sex }\end{array}$} & \multirow[b]{2}{*}{$\begin{array}{c}\text { Clinical } \\
\text { Presentation }\end{array}$} & \multicolumn{4}{|c|}{ Aneurysm Characteristics } \\
\hline & & & $\begin{array}{l}\text { Neck } \\
(\mathrm{mm})\end{array}$ & $\begin{array}{l}\text { Width } \\
(\mathrm{mm})\end{array}$ & $\begin{array}{c}\text { Dome } \\
(\mathrm{mm})\end{array}$ & Location \\
\hline 1 & $44 / F$ & Incidental & 6 & 6 & 7 & MCA \\
\hline 2 & $64 / M$ & Incidental & 6 & 7 & 8.5 & Vertebral artery-PICA \\
\hline 3 & $35 / F$ & Incidental & 5.5 & 6.5 & 8 & MCA \\
\hline \multirow[t]{2}{*}{4} & $57 / F$ & Incidental & 10 & 11 & 11 & Basilar tip \\
\hline & & & 7 & 11 & 13 & MCA \\
\hline 5 & $42 / F$ & Incidental & 5 & 5.5 & 6 & MCA \\
\hline 6 & $52 / F$ & Incidental & 6.5 & 7.5 & 8.5 & MCA \\
\hline 7 & $64 / F$ & Incidental & 5 & 10 & 13 & Basilar tip \\
\hline 8 & $42 / M$ & Incidental & 5.5 & 6.5 & 8.5 & ICA bifurcation \\
\hline 9 & $58 / \mathrm{M}$ & Recanalization & 6 & 8 & 9 & AcomA \\
\hline 10 & $62 / F$ & Recanalization & 5 & 6 & 8 & MCA \\
\hline 11 & $58 / F$ & Incidental & 6 & 6 & 7 & MCA \\
\hline 12 & $54 / F$ & Recanalization & 10 & 11 & 18 & MCA \\
\hline 13 & $69 / F$ & Incidental & 6.5 & 8 & 9 & AcomA \\
\hline 14 & $51 / \mathrm{F}$ & Incidental & 4.5 & 5.5 & 7 & MCA \\
\hline 15 & $58 / \mathrm{M}$ & Incidental & 6 & 7 & 9 & MCA \\
\hline 16 & $71 / F$ & Incidental & 4.5 & 5 & 6 & MCA \\
\hline 17 & $51 / F$ & Incidental & 7 & 9 & 12 & MCA \\
\hline 18 & $54 / F$ & Incidental & 5 & 5.5 & 3.5 & MCA \\
\hline 19 & $64 / M$ & Incidental & 5.5 & 8.5 & 7 & MCA \\
\hline
\end{tabular}

Note:-AcomA indicates anterior communicating artery.

acteristics are detailed in Table 1. All patients were asymptomatic. Mean aneurysm size was $9 \mathrm{~mm}$ (range, $6-18 \mathrm{~mm}$ ).

\section{Device Description}

The self-expanding WEB is a globular braided nitinol mesh. The device is composed of inner and outer braids held together by proximal, middle, and distal radiopaque markers. Depending on the device, the inner and outer braids are 108 wires or 144 wires. Therefore, blood flow into a WEB-embolized aneurysm initially encounters 2 layers of wires comprising 216 or 288 wires with an average interwire distance of 106 or $147 \mu \mathrm{m}$, respectively. The WEB implant is deployed or retrieved before detachment-in a manner similar to that of conventional endovascular coil systems by using microcatheters with an internal diameter $\geq 0.027$ inches (WEB width between 5 and $8 \mathrm{~mm}$ ) or $\geq 0.032$ inches (WEB width between 9 and $11 \mathrm{~mm}$ ). Once the device is deployed, it is fully retrievable. If a satisfactory position is achieved, an electrothermal detachment is applied, providing instantaneous detachment. The mesh structure of the WEB provides a stentlike apposition to the aneurysm wall. Numerous diameters (5-11 mm) and heights (3-9 $\mathrm{mm}$ ) are currently available.

\section{Treatment Technique}

The WEB is designed for treatment of saccular bifurcation aneurysms with a dome-to-neck ratio $\geq 1$. To assure a proper orientation of the device, the delivery must generally be a direct orthogonal (perpendicular) angle between the long axis of an aneurysm and the center line of its parent artery. Deployment of the WEB is best when it is not in contact with the wall of an aneurysm and when this angle is $<45^{\circ}$.

Endovascular treatment was performed on either a biplane flat panel digital subtraction unit (Allura Xper 20/10; Philips, Best, Netherlands) or on a single-plane flat panel digital subtraction unit (Infinix VF-i/SP; Toshiba, Tokyo, Japan). Endovascular procedures were performed with the patient under general anesthesia and systemic heparinization. The adequacy of systemic anticoagulation was monitored by frequent measurements of the ACT. A baseline ACT was obtained before the bolus infusion of 5000 IU heparin, and every 30 minutes thereafter. The bolus infusion was followed by a continuous drip (1000-1500 $\mathrm{IU} / \mathrm{h}$ ), for doubling the baseline ACT. No routine antiplatelet medication was used before EVT, except if the patient was already under antiplatelet medication for another reason (ie, EVT of another IA by stent-assisted coiling). Unilateral femoral access was obtained and a long high-support introducer (IVA; Balt, Montmorency, France) was placed within the cervical portion of the parent artery. Then, a Fargo Max catheter (Balt) was placed within the introducer to reach the cavernous ICA or the V3-V4 segments of the vertebral artery.

To deliver the WEB, different microcatheters were used and placed at the base of the aneurysmal sac: a Rebar 27 or a Marksman microcatheter (ev3, Irvine, California) for WEB width $\leq 8 \mathrm{~mm}$ and a 0.038 -inch DAC microcatheter (Concentric Medical, Mountain View, California) for larger devices. Because of the lack of any experience with this type of device, we have chosen to be very conservative, trying not to oversize the device. Procedure duration was recorded and defined as the time elapsed between the beginning of navigation with the delivery microcatheter and satisfactory WEB placement. Heparin was stopped at the end of EVT in most patients, and a femoral closure device was placed. No medication was administered after EVT except in case of complications.

\section{Clinical Outcome}

Senior neurointerventionalists (B.L., B.M., L.C., D.B.) recorded the clinical course, including worsening of symptoms and death. Clinical outcome was graded at discharge, and at 3, 6, and 12 months, according to the modified Rankin Scale. ${ }^{3}$

\section{Anatomic Outcome}

Anatomic results were classified as complete occlusion (no contrast filling the aneurysmal sac), near-complete occlusion (residual contrast filling the aneurysmal neck), and incomplete occlusion (residual contrast filling the aneurysmal body) (Table 2).

Follow-up DSA was obtained at times ranging between 3 and 12 months. Imaging files were reviewed independently for all patients by 2 neurointerventionalists (G.D., C.S.), blinded to the observations made by the physicians performing the treatments and follow-up examinations. On all follow-up studies, improvements or worsening of anatomic results were noted, compared with the immediate posttreatment angiogram. 
Table 2: Anatomic outcome in 18 patients with 19 treated aneurysms

\begin{tabular}{|c|c|c|c|c|}
\hline \multirow[b]{2}{*}{ No. } & \multicolumn{4}{|c|}{ Aneurysm Occlusion } \\
\hline & Immediate & $\begin{array}{l}\text { 3-Month } \\
\text { Control }\end{array}$ & $\begin{array}{c}\text { 6-Month } \\
\text { Control }\end{array}$ & $\begin{array}{c}\text { 12-Month } \\
\text { Control } \\
\end{array}$ \\
\hline 1 & $\mathrm{NC}$ & $\mathrm{NC}$ & $\mathrm{NC}$ & $\mathrm{NC}$ \\
\hline 2 & $\mathrm{NC}$ & $\mathrm{NC}$ & $\mathrm{NC}$ & \\
\hline 3 & $\mathrm{NC}$ & $\mathrm{NC}$ & $\mathrm{NC}$ & $\mathrm{NC}$ \\
\hline \multirow[t]{2}{*}{4} & $\mathrm{NC}$ & $\mathrm{NC}$ & $\mathrm{NC}$ & $\mathrm{NC}$ \\
\hline & 1 & I & & \\
\hline 5 & 1 & I & $\mathrm{NC}$ & $\mathrm{NC}$ \\
\hline 6 & $C$ & & & \\
\hline 7 & I & I & & C \\
\hline 8 & NC & NC & NC & \\
\hline 9 & $\mathrm{NC}$ & $\mathrm{NC}$ & $\mathrm{NC}$ & \\
\hline 10 & $\mathrm{NC}$ & $\mathrm{NC}$ & $\mathrm{NC}$ & \\
\hline 11 & 1 & $\mathrm{NC}$ & $\mathrm{NC}$ & \\
\hline 12 & $\mathrm{NC}$ & & I & \\
\hline 13 & $\mathrm{NC}$ & $\mathrm{NC}$ & & \\
\hline 14 & $\mathrm{NC}$ & $\mathrm{NC}$ & $\mathrm{NC}$ & \\
\hline 15 & $\mathrm{NC}$ & $\mathrm{NC}$ & $\mathrm{NC}$ & \\
\hline 16 & $\mathrm{NC}$ & $\mathrm{NC}$ & $\mathrm{NC}$ & \\
\hline 17 & 1 & I & $\mathrm{NC}$ & \\
\hline 19 & $\mathrm{NC}$ & $\mathrm{NC}$ & & \\
\hline
\end{tabular}

Note:-C indicates complete; NC, near complete; I, incomplete.

\section{RESULTS}

\section{Angle between the Aneurysm and Microcatheter}

The angle between the axis of the delivery microcatheter tip and the long axis of the aneurysm was between $0^{\circ}$ and $25^{\circ}$ in all patients except 2. In Patients 7 and 8 , this angle was close to $45^{\circ}$.

\section{Endovascular Procedure/Technical Issues}

Treatment failure with the WEB occurred in only 1 patient (patient 18) who had a wide-neck MCA bifurcation aneurysm with a 5.5-mm width and a 3.5-mm dome. Two different WEB devices (a 6-mm width/3-mm height and a 5-mm width/4-mm height) were delivered within the sac; one was too large (significant protrusion within the parent artery) and the other was too small (significant aneurysm remnant), so the aneurysm was treated with stent-assisted coiling. In the remaining 18 patients with 19 aneurysms, 20 WEB devices were placed; patient 12 was treated with 2 WEBs. In all instances, all devices were inserted and pushed through the delivery catheter with acceptable friction. Because of the relative stiffness of the WEB, tension within the delivery microcatheter was constantly relieved while pushing the device to avoid sudden movement of the distal tip of the catheter within the aneurysm. Then, the WEB was carefully delivered within the aneurysm.

Deployment was successfully performed in all except 1 patient (patient 6) in whom the WEB was not completely deployed. This patient had an MCA bifurcation aneurysm with a bleb at the base. EVT was performed in a single-plane angiosuite so that only 1 working view was available. The WEB was delivered by using a DAC microcatheter. Because of its stiffness, the distal tip of the DAC did not deflect during WEB deployment and the device went directly within the bleb. The WEB remained compressed within the bleb, leaving the aneurysmal sac patent. Immediate angiographic control showed a bleb rupture. After heparin reversal, quick coiling of the sac was performed with an additional glue injection at the bleeding site.

Among these 18 patients with 19 aneurysms, adjunctive treat- ment was required in 2 other patients (patients 5 and 11) in whom the base of the WEB protruded within the MCA bifurcation after detachment, causing a slowing of flow in a branch. Therefore, IV abciximab was administered, and a self-expandable stent (Solitaire; ev3) was placed within the involved branch, and it completely restored the flow.

Procedure duration was $<20$ minutes in 17 cases and $>90$ minutes in 2 cases (patients 7 and 8 ). In these latter 2 patients, the angle between the catheter tip and the long axis of the aneurysm was close to $45^{\circ}$, so on deployment, the distal tip of the WEB was immediately coming close to the aneurysm wall. To avoid this, the catheter had to be reshaped and the WEB had to be repositioned several times.

Detachment of the WEB was immediate in all except 1 patient (patient 2) in whom the first WEB did not detach, so another device had to be used.

\section{Clinical Outcome}

Among 18 treated patients, 16 were discharged home 48 hours after EVT with normal neurologic examination findings (mRS, 0 ). Patient 6 , who experienced an aneurysm rupture, sustained a residual hemiparesis ( $\mathrm{mRS}, 3)$ at follow-up because of an MCA infarction. In patient 7 who had a basilar tip aneurysm, the procedure was uneventful but the patient woke up with a gait instability (mRS, 2). MR imaging was performed and showed a partial posterior inferior cerebellar artery infarction. At follow-up, the patient completely recovered.

\section{Anatomic Outcome}

Anatomic outcome is detailed in Table 2. Immediate posttreatment angiograms showed 1 complete occlusion, 13 near-complete occlusions, and 5 incomplete occlusions.

A complete occlusion was achieved in patient 6 , who experienced an aneurysm rupture and had to be treated with additional coils (and glue). Because of the wide neck of this aneurysm, this, however, resulted in some parent artery obstruction.

In 13 cases with a near-complete occlusion, the remnant was mostly seen as residual filling in the tiny concavity situated at the location of the proximal marker on the WEB (Figs $1 C$ and 2C). Incomplete occlusion was seen in 5 cases: 3 with persistent filling inside or below the WEB (patients 4, 5, 7) and 2 with filling alongside the WEB (patients 11 and 17). In Patient 7 with a large basilar tip aneurysm, a significant residual sac was present immediately after treatment and it remained stable at 3 months (Fig 3B). This was treated further by stent-assisted coiling (during EVT of an associated wide-neck superior cerebellar artery aneurysm), and a complete occlusion was achieved that remained stable at follow-up (Fig 3C). Among the remaining 4 patients with incomplete occlusions, 2 had received IV abciximab after WEB placement because stent placement was required (patients 5 and 11) and 2 were on aspirin before WEB placement because they already were being treated for another aneurysm by stent-assisted coiling. However, in each of these 5 cases, the distal part of the WEB and the aneurysm dome were occluded at the end of EVT.

Angiographic follow-up was obtained in all patients, including 4 at 3 months, 10 at 6 months, and 5 at 12 months (mean, 6 months). Of these 19 aneurysms, 15 were either better $(n=7)$ or 

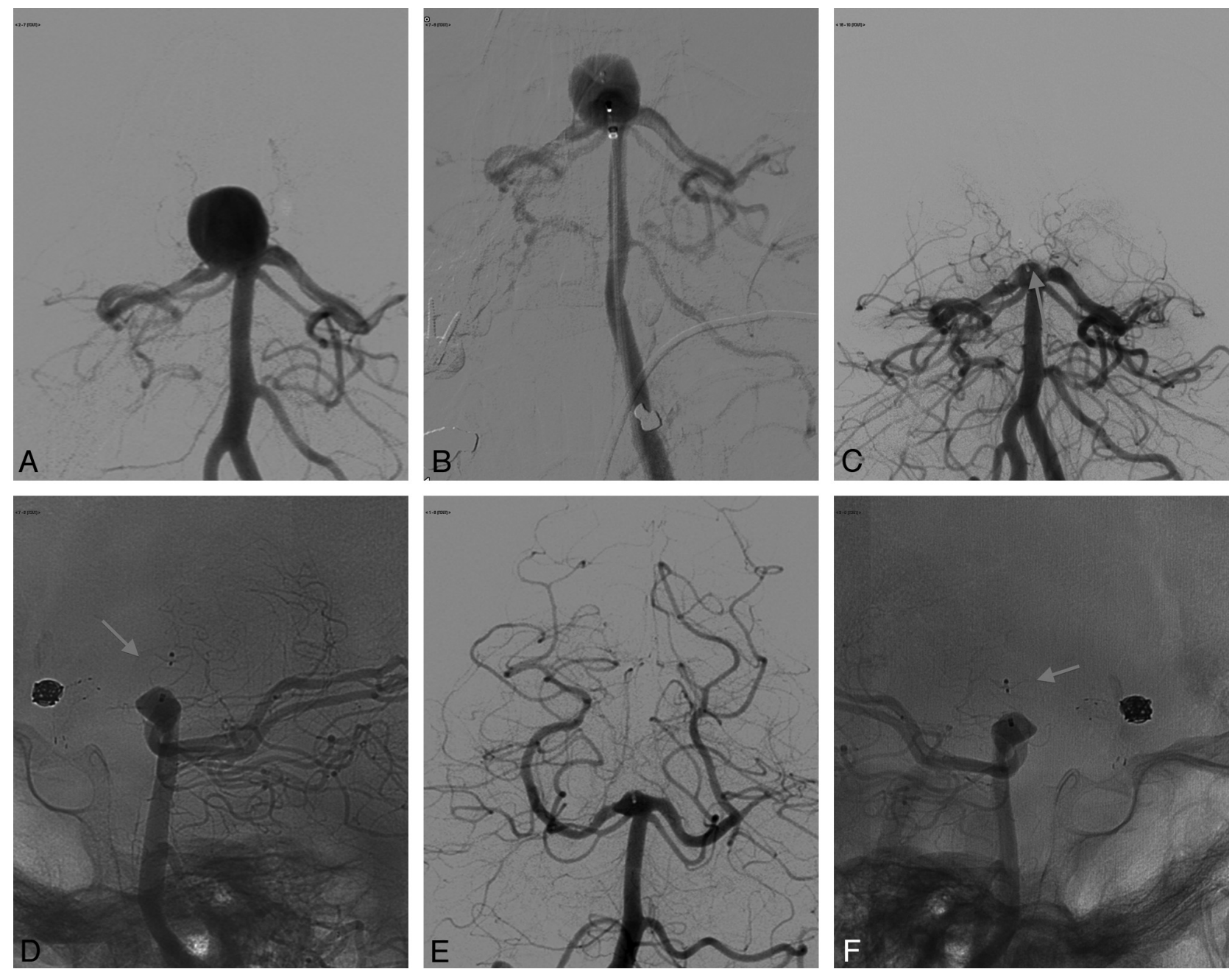

FIG 1. Incidental aneurysm in a 57-year-old woman. $A$, Conventional angiography shows a very wide-neck basilar tip aneurysm. $B$, Placement of the WEB device within the aneurysmal sac. $C$, Angiographic control at the end of EVT shows a small-neck remnant (arrow) that is mostly due to the design of the WEB that has a concave proximal recess. D, Unsubstracted lateral view at the end of EVT shows the WEB device (arrow). E, Angiographic control at 12 months shows a stable aneurysm occlusion. $F$, Unsubstracted lateral view at 12 months shows the WEB device that remains unchanged both in shape and size (arrow).
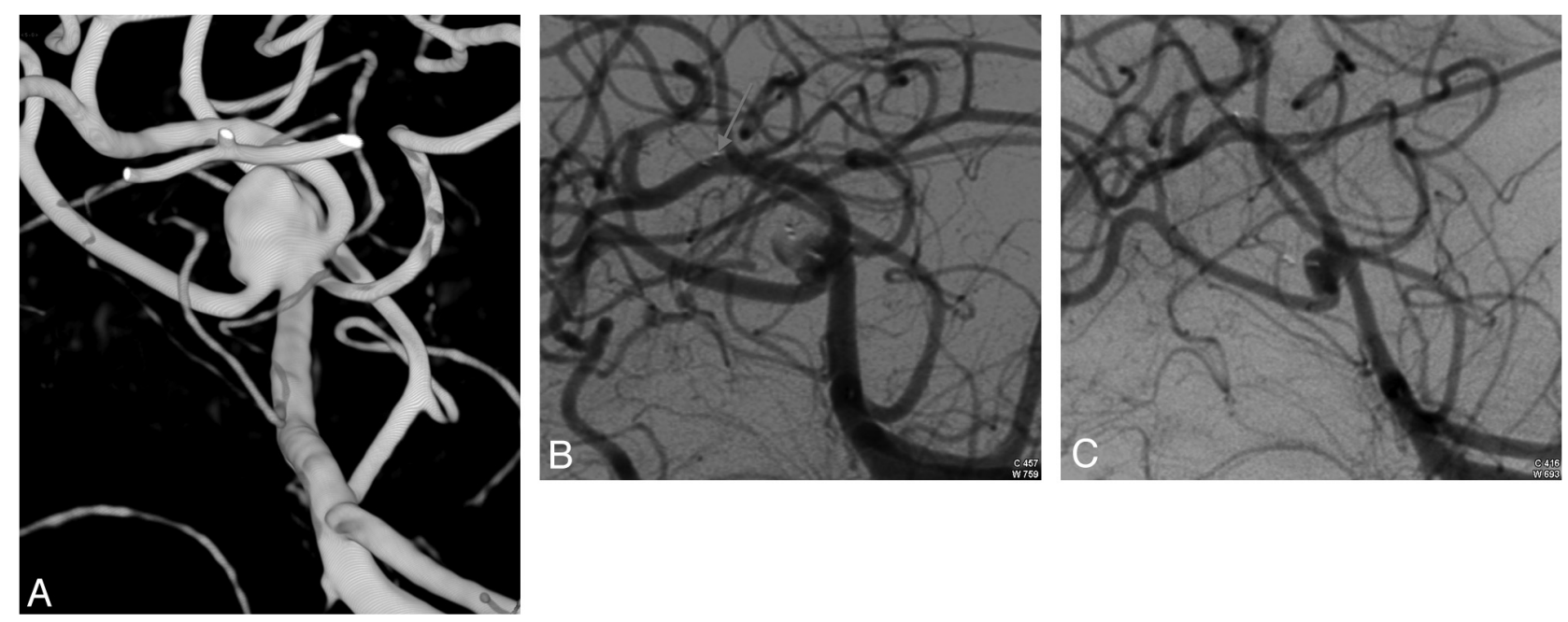

FIG 2. Incidental aneurysm in a 58-year-old woman. $A, 3 D$ angiography shows a wide-neck MCA trifurcation aneurysm. $B$, EVT was performed and resulted in a WEB protrusion within a branch; IV abciximab was administered and a Solitaire stent (arrow) was placed, achieving an incomplete occlusion and patency of the stented branch. C, Angiographic control at 6 months shows a stable small-neck remnant. 

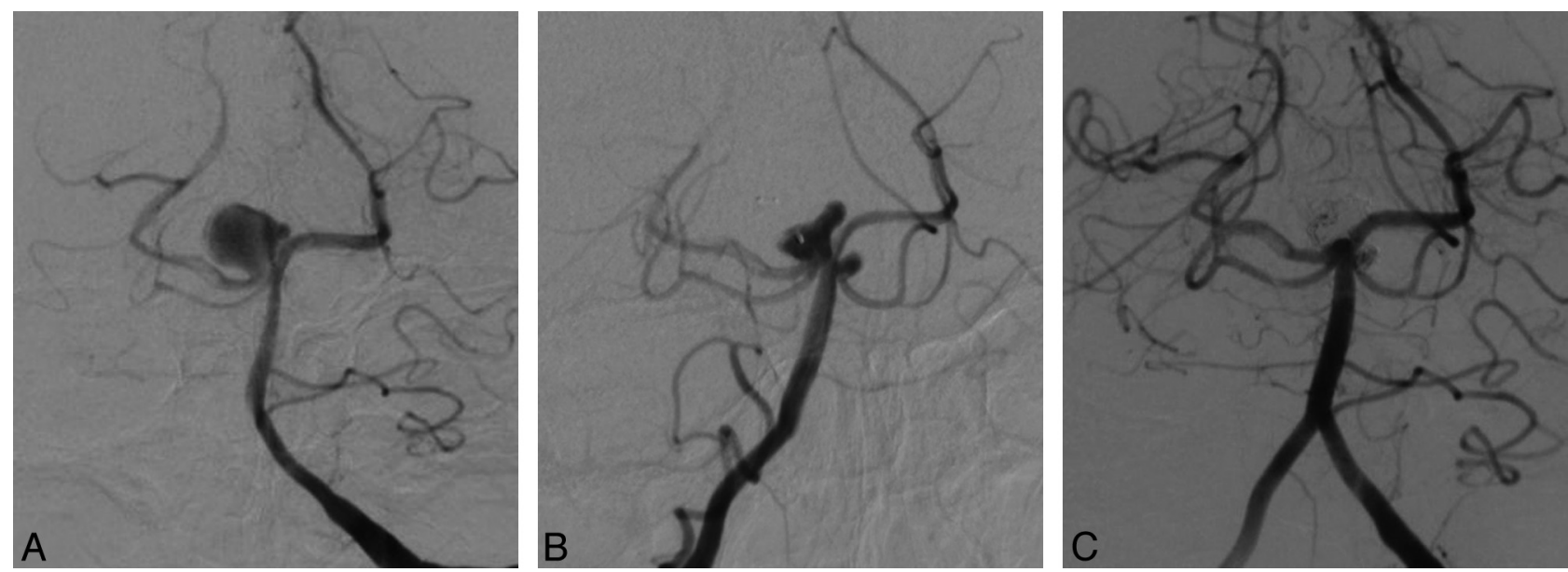

FIG 3. Incidental aneurysm in a 64-year-old woman. $A$, Conventional angiography shows a 13-mm basilar tip aneurysm with a 5-mm neck. $B$, Angiographic control at the end of EVT shows an incomplete aneurysm occlusion. $C$, Angiographic control after complementary treatment by stent-assisted coiling shows a complete aneurysm occlusion.

the same $(n=8)$ at follow-up; 4 were worse. Final anatomic outcome included 2 complete occlusions, 15 near-complete occlusions, and 2 incomplete occlusions.

\section{Illustrative Cases}

Case 1. A 57-year-old woman (patient 4) presented with multiple incidental IAs, including a large basilar tip aneurysm. Conventional angiography showed an 11-mm aneurysm with a $10-\mathrm{mm}$ neck (Fig 1A). Endovascular treatment was performed by WEB placement (Fig 1B) achieving a small neck remnant that was mostly due to persistent filling of contrast in the concavity at the base of the WEB (Fig 1C, -D; arrows). Follow-up angiographic controls at 3,6, and 12 months (Fig $1 E,-F$ ) showed a stable occlusion. The WEB device remained unchanged both in shape and size at follow-up (Fig $1 D,-F$; arrows)

Case 2. A 58-year-old woman (patient 11) presented with an incidental MCA trifurcation aneurysm. 3D angiography showed a very wide-neck aneurysm (Fig 2A). Endovascular treatment was performed by WEB placement. Angiographic control showed WEB protrusion within 1 of the trifurcation branches with slowing of the flow. Therefore IV abciximab was administered, and a Solitaire stent (Fig $2 B$, arrow) was placed. The involved branch remained patent, and there was no associated neurologic change (Fig 2B). Follow-up angiographic controls at 3 and 6 months (Fig $2 C)$ showed a stable small-neck remnant.

Case 3. A 64-year-old woman (patient 7) presented with an incidental basilar tip aneurysm. Conventional angiography showed a 13-mm aneurysm with a 5-mm neck (Fig $3 A$ ). Endovascular treatment was performed by WEB placement, achieving an incomplete aneurysm occlusion (Fig 3B). Angiographic control at 3 months showed a stable occlusion, and further stent-assisted coiling was performed, achieving a complete occlusion (Fig 3C).

\section{DISCUSSION}

This initial study reports a series of patients with IAs treated by the WEB intrasaccular flow disrupter. It shows that this new technique is feasible for EVT of wide-neck bifurcation IAs.

\section{Procedure Duration/Patient Selection}

The procedure duration may be reduced compared with other available techniques. If one considers that we have included only patients with complex IAs that would "classically" require a several-hour procedure (either surgical or endovascular), the use of the WEB, in general, brings a significant improvement in treatment time to this subgroup of patients. This might decrease the procedure-related morbidity by reducing thromboembolic events and anesthesia time. However, in 2 patients (patients 7 and 8 ), the procedure was significantly longer because of the difficulty associated with delivery and satisfactory positioning/deployment of the WEB in these aneurysms. This occurred because the long axis of the aneurysm was not in line with the center line of the parent artery, resulting in the need for repositioning and/or catheter shaping. In these 2 patients, the angle between the microcatheter axis and the long axis of the aneurysm was close to $45^{\circ}$ so that during initial WEB deployment the device would have had some contact with the aneurysm wall. As a remedy, the delivery catheter had to be reshaped and the WEB had to be repositioned several times to finally allow a safe deployment.

\section{EVT with the WEB}

Despite the small size of the present series, our results show that EVT of IAs with the WEB is a feasible new technique. Moreover, the availability of the WEB might enlarge indications of EVT because it allows treating IAs that are not amenable to conventional endovascular techniques. Indeed, wide-neck terminal/bifurcation IAs require treatment with a Y-or X-stent placement or even the waffle-cone technique. ${ }^{4,5}$ These techniques may be difficult in some IAs and also have other major limitations, including the need for dual antiplatelet medication, which may be associated with higher complication rates, ${ }^{6}$ the unknown long-term tolerance of 2 stents within the same vessel, and the high rate of recanalization with the waffle-cone technique., ${ }^{4,5}$ Therefore, the WEB might have potential advantages over these techniques, but this needs to be confirmed in larger studies evaluating the efficacy and stability of this new therapeutic option.

From a technical point of view, the key points for EVT with the 
WEB are the support of the delivery microcatheter and the WEB size selection. A telescopic access system is very useful to ensure stable navigation and deployment of the WEB. For adequate WEB sizing, the width of the device should be equal to or greater than the aneurysm width. If the device is larger than the sac, it will elongate, and care must be taken after delivery to assess whether there is any significant parent artery intrusion at the aneurysm ostium. If this is present, the device may be removed and a smaller size WEB may be deployed. In most instances, upsizing the device by $1 \mathrm{~mm}$, when the first device is too small, is sufficient and appropriate. However, as seen in the case to be described below, it would be beneficial to be able to upsize, in some aneurysms, by 0.5 $\mathrm{mm}$. We experienced 1 failure in patient 18 , who had an aneurysm with a $5.5-\mathrm{mm}$ width that was not suitable for either a 5- or a 6-mm WEB. These half-millimeter sizes are expected to be available soon. Fortunately, the WEB is fully retrievable once deployed, and it may be exchanged for a more optimal device if sizing is not correct. As shown in 2 of our patients, should there be inadvertent intrusion of the WEB into the parent artery or adjacent branches, a stent may be used to avoid flow obstruction (patients 5 and 11). Last but not least, the use of a WEB does not prevent using other conventional embolic material such as detachable coils if the aneurysm occlusion is incomplete (Fig 3).

\section{Anatomic Outcome}

Our anatomic results are encouraging if one considers the anatomic features of the aneurysms in this series (ie, patients with unruptured bifurcation/terminal-type aneurysms, having wide necks and a mean size of $9 \mathrm{~mm}$ ). Indeed, in this group of IAs that have the highest recanalization rate when treated with coils, nearcomplete occlusion was immediately achieved in most patients, and it either improved or remained stable at follow-up in most cases. Moreover, the small remnant at the base of the sac was frequently due to the design of the WEB device that has a concave proximal recess that is filled with contrast material. At follow-up, most of these remnants remained stable or even remodeled positively. In time, modification of the WEB design may further reduce this feature. It could be, however, that the current design is beneficial to aneurysm/device stability or that this type of smallneck remnant, adjacent to the very low porosity of the base of the WEB, is irrelevant to the stability of treatment. We are optimistic that the use of an intrasaccular flow disrupter with the physical characteristics of the WEB (an elasticity that resists deformation) will be associated with stable anatomic results because the mechanisms that lead to aneurysm occlusion are different from those associated with coiling. Also, the fact that the WEB resists defor- mation (Fig 1D, -F; arrows) would seem to offer hope that it will not, as do coils, undergo compaction so as to allow aneurysm recanalization.

Finally, our preliminary experience suggests that in patients who need to receive IV abciximab (and perhaps other powerful antiplatelet medication) immediate complete aneurysm occlusion may be difficult. Nevertheless, follow-up controls in the 2 such patients in our series showed a satisfactory aneurysm occlusion that either remained stable or improved.

Much more data and experience with the device are now needed to evaluate the real efficacy and long-term results of this new therapeutic approach.

\section{CONCLUSIONS}

This series showed that intrasaccular flow diversion with the WEB offers a new therapeutic option for the treatment of wide-neck bifurcation/terminal IAs.

Disclosures: Boris Lubicz-RELATED: Consulting Fee or Honorarium: Sequent Medical, * Comments: Both my institution and I received honorarium, Support for Travel to Meetings for the Study or Other Purposes: Sequent Medical, Payment for Writing or Reviewing the Manuscript: Sequent Medical, UNRELATED: Consultancy: MicroVention, ${ }^{*}$ Codman, ${ }^{*}$ Covidien, ev3, ${ }^{*}$ Sequent Medical, ${ }^{*}$ Balt ${ }^{\star}$. Gary DuckwilerConsulting Fee or Honorarium: Sequent Medical. Charles Strother-RELATED: Grant: Sequent Medical, ${ }^{\star}$ Comments: Sponsored research agreements were in place with the University of Wisconsin, Madison. This research was in regard to testing and development of the WEB device, Consulting Fee or Honorarium: Sequent Medical, Comments: consultant to the company, Support for Travel to Meetings for the Study or Other Purposes: Sequent Medical, Comments: No money was paid to me, but expenses for travel to 2 meetings where research related to the WEB was presented were assumed by the vendor, UNRELATED: Stock/Stock Options: Sequent Medical, Comments: I have stock options and stock in Sequent Medical Inc. *Money paid to the institution.

\section{REFERENCES}

1. Ding YH, Lewis DA, Kardivel R, et al. The Woven EndoBridge: a new aneurysm occlusion device. AJNR Am J Neuroradiol 2011;32:607-11

2. Pierot L, Liebig T, Sychra V, et al. Intrasaccular flow-disruption treatment of intracranial aneurysms: preliminary results of a multicenter clinical study. AJNR Am J Neuroradiol 2012;33:1232-38

3. Bonita R, Beaglehole R. Modification of Rankin Scale: recovery of motor function after stroke. Stroke 1988;19:1497-500

4. Thorell WE, Chow MM, Woo HH, et al. Y-configured dual intracranial stent-assisted coil embolization for the treatment of widenecked basilar tip aneurysms. Neurosurgery 2005;56:1035-40

5. Sychra V, Klisch J, Werner M, et al. Waffle-cone technique with Solitaire ${ }^{\mathrm{TM}} \mathrm{AB}$ remodeling device: endovascular treatment of highly selected complex cerebral aneurysms. Neuroradiology 2011;53: 961-72

6. Kim DJ, Suh SH, Kim BM, et al. Hemorrhagic complications related to the stent-remodeled coil embolization of intracranial aneurysms. Neurosurgery 2010;67:73-78, discussion 78-79 